\title{
Un Villon criollo
}

Un poeta colonial que no fué doctor, militar ni beato... Nuevas aportaciones a la biografía de Juan del Valle Caviedes

ANTeCEDENTES bibltográficos.

Desde que el primer "Mercurio Peruano" (I79I-I794) insertó una noticia acerca del poeta satírico peruano Juan del Valle Caviedes, reproducida después en la reedición de Fuentes, (I) y más aún, desde que el Coronel Odriozola dió a la publicidad los versos del "sagitario limeño" en sus Documentos literarios del Perí, (2) no ha habido visitante de nuestras letras que se haya librado de consagrar una parrafada más o menos entusiasta al autor del Diente del Parnaso.

Entre los más fervientes figuran, sin duda, el argentino Juan María Gutiérrez (3) y el insigne tradicionalista don Ricardo Palma, (4) prologuista y resurrector de su obra. Y tanta fué la fama recaída sobre aquel retoño quevedesco de nuestra literatura virreinal, que el severo Menéndez y Pelayo cedió al contagio de los panegiristas, (5) y luego coincidieron en el ditirambo José Toribio Medina, Javier Prado, Ventura Garcia Calderón, José de la Riva Agüero, Raúl Porras Barrenechea, Emilio Champion, (6) y, en general, todos cuantos nos ocupamos de los temas "criollismo", "sátira" y "costumbrismo" èn el Perú: No me escapé yo por cierto del sortilegio aquél, no obstante que entön- 
ces mis veinte años trataban de singularizarse por sus votos en contra y sus invectivas más o menos bien documentadas y más o menos vehementes. (7) El General Mendiburo, ajeno a la literaria pendencia, tampoco se apartó del ritmo elogioso impuesto ya por la costumbre, y contribuyó a la biografía de Caviedes con un dato referente a la madre del poeta. (8)

Corolario de todo ello es que hay tres ediciones de la obra de Caviedes: las de Odriozola y Palma (9) y la que hicimos en I924 o I925, Daniel Ruzo y yo, omitida por Ventura García Calderón en su reciente comentario inserto en un tomo de la "Biblioteca de Cultura Peruana". (Io)

Los DOCUMENTOS INÉDITOS.

Pero acaso, y a pesar de que Champion ha querido revalorar de nuevo al lejano autor del Diente del Parnaso, su auge habriase esfumado para los estudiosos, si no fuera porque hace poco el joven investigador don Guillermo Lohman Villena encontró dos documentos inéditos (II) acerca del personaje, documentos que, si bien lo sitúan más cerca de la realidad, no por eso rectifican en forma definitiva, como cree Lohman, la silueta sustancial que tenemos ya de Caviedes, puesto que subsisten sus características tanto literarias como personales, refrendadas - no eliminadas- precisamente por el testamento ahora exhumado.

Lohman asegura, en las líneas prömiales a sus descubrimientos, que todos los datos existentes sobre la vida del poeta "son obra de la imaginación"; que con los documentos que él exhibe "queda desvirtuada en absoluto la fantástica leyenda que infundadamente se había forjado en torno del chistoso y agudo galenófobo, pues de ello se infiere que ni nació en Lima, ni era de baja estofa... ni era pervertido, ni ocupaba un cajón de la Ribera, según le atribuyeron sus pseudobiógrafos". En realidad, lo que sí "queda desvirtuado" es que fuera limeño de nacimiento, pero lo demás o. nọ parece tan a las claras, 0 , al revés, 
resulta corroborado del propio trabajo del acucioso y meritorio investigador a quien aquí gloso.

Y esta discrepancia entre el documento y la exégesis es lo que me convida a repasar de nuevo la figura de nuestro insigne satírico, fundándome, además, en que algo fchaciente aporté hace casi veinte años a la mejor ubicación de su vida moral: rectifiqué la fecha de su muerte, recordé que había un romance no coleccionado en su obra inipresa, y descubrí - yo también Colón- un soneto inédito, en los manuscritos de la Biblioteca Nacional de Lima, soneto que reproduce de mi citado libro García Calderón en el volumen a que me he referido. (12)

Dos Caviedes o uno solo.

La versión sancionada por las autoridades en la materia -Mendiburo, Palma, Odriozola, Gutiérrez, etc.- es que Juan del Valle Caviedes había nacido en Lima, de padre español y madre criolla; dato este último debido a Mendiburo. (13) Como Pálma señaló el año de $\mathrm{r} 692$ como el de su muerte y se atuvo a un verso de Caviedes en que, so capa de "no llegaré a vièjo" anuncia que morirá antes de los ctrarenta, se fijó el nacimiento en 1652. Como yo descubri que, en 1694 , aparecía un soneto de. Caviedes en un libro del doctor Bermejo, siguiendo la norma de no dejarlo vivir sino cuarenta años, propuse que la fecha del natalicio pudo ser 1654 . Como ahora Lohman ha descubierto una escritura de 1695 en que se alude a Caviedes a modo de descubridor de una mina estacada en Huarochiri, resultaria aunque aquí no se trata de que Caviedes figurara en el acto notarial pertinente, sino que fué aludido en él- que le postergariamos la muerte un año, a I695, y el nacimiento podría quedar ubicado (siempre dentro de la sentencia a que no viviera sino la cuarentena) en 1655 . Esto en cuanto a la cronología: De cllo se deduce, hoy igual que ayer, poco cierto $y$ mucho problemático. 
La biografía consagrada aseveraba que a' los veinte, Caviedes fué llevado a España por su padre, y que residió en la península tres años, regresando al Perú a causa de la muerte de aquél. De ahí fluye que no se le consideraba tan desdichado en dinero; puesto que el viaje era costoso. Tal noticia no ha sido rectificada ni ratificada fehacientemente. Está en pie.

Se había admitido que, más o menos hacia $168 \mathrm{i}$, o sea en los albores de sus supuestos treinta años, sintió la vocación literaria, y que por aquel entonces se casó. Lo primero es posible todavía que sea cierto; lo segundo, como hecho, queda robustecido por la partida de matrimonio que exhibe Lohman, sólo que tal acto fué llevado a cabo el $x_{5}$ de marzo de $167 \mathrm{r}$, en la Iglesia de la Catedral de Lima, con doña Beatriz de-Godoy Ponce de León, natural de Moquegua, hija legítima de don Antonio de Godoy Ponce de León y de doña Maria de Guerra Falcón. Este dato y el del nombre de los padres de Caviedes son dos aportes de Lohman: los últimos fueron don Pedro del Valle Caviedes, seguramente español, y doña María de Caviedes, seguramente del mismo origen, porque el poeta vió la liz en la Villa de Porcuna, Andalucía, y no en Lima como hasta aquí se había dicho.

En r683, cuando dictó su testamento, Caviedes no era viudo, puesto que ahí habla de su esposa y de sus hijos, pero en su obra - ¿ real toda ella?, ¿atribuida en parte?- figura una composición "A la muerte de mi esposa", de donde, se inferiría; o que fué casado dos veces, y eso no es posible a terior de los documentos que publica Lohman; o que el testamento fué anterior a la muerte, muy anterior a la muerte de Caviedes, y que enviudó después de otorgarlo; o que la composición mencionada es apócrifa. Lo más probable es lo segundo, aunque, dicho sea de paso, entre $E l$ Diente del Parnaso, de género festivo y satírico, con una inefable filiación quevedesca, y las Poesias varias, de índole elegíaca muchas de ellas, hay una notable diferencia, tan notable que bien pudieran pertenecer a autor distinto. 
La biografía consabida ha pintado a Caviedes como una especie de Villon criollo. Mujeriego, probable víctima del "mal francés", torturado por los médicos limeños, a quienes agrede con inolvidable saña, aficionado al vino, lleno de deudas, instalado en uno de los "cajones de la Ribera", o sea los tenduchos de los bajos del Palacio de Gobierno (como hoy, en Quito) de donde sacó el mote de "el poeta de la Ribera" con que es conocido en la leyenda y en la historia. Veamos qué sobrevive de todo esto.

\section{EL "VilLon CRIOLlo".}

El acto mismo de su matrimonio huele a cosa non sancta. ¿Por qué? Por el tenor del acta publicada por Lohman. En ella se consigna que la esposa de Caviedes se casó siendo "colegiala de dicho colegio" (el de la Caridad de Lima) y que el matrimonio se llevó a cabo previa dispensa de "las tres amonestaciones que dispone el santo Concilio de Trento". Ambas circunstancias inclinan a pensar que Caviedes anduvo más de prisa que lo conveniente y que el casorio fué remedio aplicado con prontitud para parchar el estropicio, a manera de remiendo sacramental.

El "poeta de la Ribera", el que zaliería con tanta travesura a los médicos y jeringueros limeños, tenía un ánimo desaprensivo, poco escrupuloso; y que lo fué está comprobado por el testamento descubierto por Lohman, donde, el 26 de marzo de 1685, por ante el escribano Diego Fernández Montano, cuenta las siguientes proezas más de acuerdo con "una baja estofa" moral que con la elevada que correspondió al primo de un connotado personaje colonial, mencionado en el trabajo que comento.

Dice Caviedes: que me entierren de limosna y que mis albaceas la pidan para que me digan algtnas missas por mi alma. y la forma de mi entierro devo a los dhos albaceas para que la hagan conforme a mi muchu pobressa... 
Manda pagar a Joseph de Oquendo, con un aderezo de espada y daga; cierta deuda que le tenía; declara deberle a un mercachifle llamado Pedro la suma de doce (sic) pesos; item más, -"algunas cantidades de ps (pesos) a algunas personas"; item más, confiesă que engañó a Manuel de Fontidueñas, "caxonero"; empeñándole en seis pesos un mate guarnecido de plata, que no valía tanto; item más, dice que había cobrado a unos indios dinero a cuenta de cien pesos que le debían a su suegro, y pido y ruego a mi suegro gue si hubiere alguna demasia no se lo cobre a los dhos indios y me lo perdone Dios; item más, deja estampado que empeñó en cuarenta pesos una sortija de su prima que le había entregado para que la empeñase en veintidós; item más, deja en claro que, a sabiendas del daño que hacía, había presentado una denuncia falsa contra Miguel Sánchez de la Barreda, y, naturalmente, a pique quizás de morir, demanda rectificación y disculpa.

Como se ve, la silueta del Villon peruano no se rectifica, sino se perfila mejor como tal, con lo que Lohman ha descubierto, de suerte que la leyenda se confirma y se precisa, en vez de desvanecerse; eso, suponiendo que fuera leyenda to que apareció en "El Mercurio Peruano", cuyos acuciosos redactores poseyeron, sin duda, en 1790 y tantos, mejores y más cercanos datos sobre el "poeta de la Ribera", lo que también se confirma con una frase que Lohman reproduce, extrayéndola de un documento exhumado por el erudito jesuíta Rubén Vargas Ugar: te hace poco tiempo. (14)

Del testamento sólo resulta un legado positivo: sus cinco hijos (cuatro varones y una hembra) desaparecidos (porque de los versos no habla). El resto son deudas, trampillas, duros menesteres de un hombre agobiado por la miseria. Desde luego, nadie caerá en el absurdo de imputar inescrupulosidades a tan donoso poeta, ya que iguales o peores deshonestidades crematisticas cometieron grandes ingenios, entre ellos Cervantes, sin que se afee su celebridad, pero no es tampoco justo dejar limpio 
como patena un nombre, cuyo principal atractivo reside en haber sido bohemio en una época que la historia ritual nos pinta como periodo incapaz de admitir nada que riñese con lo ordinario.

La Colonia tuvo de todo: funcionarios bobalicones, cagatintas engorrosos, virreyes soberbios o mentecatos, licenciosos o beatos; monjas, damas estiradas y rameras; mercaderes, indios, criollos, mestizos, mulatos, negros y ladrones, santos, señores puntillosos, caballeros de la bolsa ajena, tramposos, tahures, ganapanes... Una sociedad sin bribones habría sido peor que un bostezo en sala de música. Lo que ocurre es que la historia oficial siempre carece de imaginación, y los desprovistos de ella se refugian en la simpleza y la rutina.

Caviedes poseyó el dón de romper el cerco de la somnolencia de los funcionarios y los devotos. Más limeño que los limeños, tan andaluz como limeño - se equivalen- persignó con motes a los médicos y sangredos de su tiempo, aunque rindió pleitesía a Bermejo y Roldán, otra de sus víctimas en otros días. Acaso, como todos, sintiéndose morir, dióle en tomar en serio a la medicina allá por el año de I694. : Pero antes, clavó pullas indelebles sobre espaldas, frentes y jorobas. Oigámoste, si no, cuando empieza a describir a cierto médica a quien llamaban Corcovado:

\author{
Mojiganga de la física, \\ tuerto èn derechos de párroco, \\ fué tu concepción incógnita \\ semen de flojos espárragos, \\ que corcova tan acérrima \\ no la concilian los rábanos...
}

$\mathrm{Y}$, picaresco y mujeriego, tentado por la carne prieta; carne de pecado, según dirían Juan y Ulloa, ( I5) confirma el entronizamiento sensual de las morenas en estos cuatro versos donairosos y provocativos: 
porque todo lo trigueño

anda caro el día de hoy.

Y tanto, que la Perricholi, un siglo después, se puso "tan cara" que sometió a su lascivo señuelo al cascarrabias y avaro don Manuel de Amat, guerrero, mandón, y largo tiempo virrey del Perú.

\section{Luis Alberto Sánchez.}

Santiago de Chile, 1939.

(1).- "El Mercurio Peruano", reed. de don Manuel Atanasio Puentes, t. 8. p. 6.

(2).-M. de Odriozola, Docïmentos̈ literarios del Peri, t. V, Lima, 1873.

(3).-Juan María Gutiérrez, estudios diversos sobre literatura colonial publicados en "El Correo del Perú", t. V, Lima, 1875.

(4).-Ricardo Palma, Flor de Academias, Lima, I899, p. 336.

(5):-Menéndez y Pelayo, Antología de la poesia hispanoantericana, t. III, Madrid, I894, e Historia de la poesia hispanoantericana, t. II, Madrid, I913.

(6).-J. T. Medina, La imprenta en Lima, t. II págs. 178-179; Javier Prado, El genio de la lengua y la literatura castellanas, etc., Lima, Igr8, págs. 65, 70 y 74; Ventura García Calderón, La literatura peritana, "Revue Hispanique", Nueva York, París, 1914; J. de la Riva Agüero, Carácter de la literatura del Perí independiente, Lima, 1905, p. 15; R. Porras, La literatura peruana, Lima, 1918; J. J. Larriva, id, Lima, I919; E. Champion, Nola biográfica de Caviedes, Revista "Letras", núm. 12, Lima, 1939, p. 12.

(7).-Sánchez, L. A., Los poetas de la colonia, Lima, 1921, págs, 186-200.

(8).-Mendiburu, Diccionario histórico biográfico del Peri, I*. ed. t. II, p. 98 .

(9).-Odriozola, o.c.-Palma, o.c.

(10).-El Diente del Parnaso, por Juan del Valle Caviedes, ed. Garcilaso, I924.

(II).-Lohman, Dos documentos inćditos sobre don $J$. del $V$. C., "Revista Histórica", t. IX, entrega III, Lima, 1937; p. 277.

(12).--Biblioteca de Cultura Peruana", t. 5. Paris, r938, El apogẹo de la literatura colonial, págs. 8-11.

(13).-Mendiburu, o.c. p.c.

(14).-R. Vargas Ugarte, Manuscritos peruanos en bibliotecas del extranjero, t. I, Lima, I935, p. 67.

(15).-Juan y Ulloa, Noticias secretas de América, Londres, 1836, (En la parte referente a Lima, acerca de la prostitución y licencia frecuentes entre las mulatas). 